\title{
$\mathrm{R} 435 \mathrm{~A}$ 를 적용한 정수기 냉동시스템의 성능평가
}

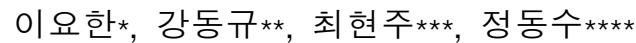

*인하대학교 대학원 기계공학과(leeyohan1@inha.edu), **인하대학교 대학원 기계공학과(dgkang@inha.edu), ***인하대학교 대학원 기계공학과(ursa@inha.edu), ****인하대학교 기계공학과(dsjung@inha.ac.kr)

\section{Performance Evaluation of R435A on Refrigeration System of Water Purifiers}

\author{
Lee, Yo-Han* Kang, Dong-Gyu** CHOI, Hyun-Joo*** Jung, Dong-SoO**** \\ *Department of Mechanical Engineering, Graduate School, Inha University(leeyohan1@inha.edu), \\ **Department of Mechanical Engineering, Graduate School, Inha University(dgkang@inha.edu), \\ **Department of Mechanical Engineering, Graduate School, Inha University(ursa@inha.edu), \\ ***Department of Mechanical Engineering, Inha University(dsjung@inha.ac.kr)
}

\begin{abstract}
In this study, thermodynamic performance of R435A is examined both numerically and experimentally in an effort to replace HFC134a used in the refrigeration system of domestic water purifiers. Even though HFC134a is used predominantly in such a system these days, it needs to be phased out in the near future in Europe and most of the developed countries due to its high global warming potential. To solve this problem, cycle simulation and experimental measurements are carried out with a new refrigerant mixture of 20\%R152a/80\%RE170 using actual domestic water purifiers. This mixture is numbered and listed as R435A by ASHRAE recently. Test results show that the system performance with R435A is greatly influenced by the amount of charge due to the small internal volume of the refrigeration system of the domestic water purifiers. With the optimum amount of charge of 21 to 22 grams, about $50 \%$ of HFC134a, the energy consumption of R435A is $11.8 \%$ lower than that of HFC134a. The compressor discharge temperature of $\mathrm{R} 435 \mathrm{~A} 8^{\circ} \mathrm{C}$ lower than that of HFC134a at the optimum charge. Overall, R435A, a new long term environmentally safe refrigerant, is a good alternative for HFC134a requiring little change in the refrigeration system of the domestic water purifiers.
\end{abstract}

Keywords : Alternative refrigerant(대체냉매), Water Purifiers(정수기), R435A(냉매 435A), HFC134a(냉매 134a), Ozone depletion(오존층 붕괴), Global warming(지구 온난화)

Submit date : 2012. 9. 18, Judgement date : 2012. 9. 24, Publication decide date : 2013. 2.1

Communication author : Jung, Dong-Soo(dsjung@inha.ac.kr) 


\section{기 호 설 명}

$\begin{array}{ll}\mathrm{COP} & : \text { 성능 계수 } \\ \mathrm{EC} & : \text { 에너지 소비량 }(\mathrm{W} \cdot \mathrm{h}) \\ \dot{m} & : \text { 유량 }(\mathrm{g} / \mathrm{s}) \\ \mathrm{T} & : \text { 온도 }\left({ }^{\circ} \mathrm{C}\right) \\ \mathrm{VC} & : \text { 체적 용량 }\left(\mathrm{kJ} / \mathrm{m}^{3}\right)\end{array}$

\section{하첨자}

$$
\begin{array}{ll}
\mathrm{dis} & \text { : 압축기 토출 부분 } \\
\mathrm{r} & \text { : 냉매 }
\end{array}
$$

\section{1. 서 론}

지난 반세기동안 염화불화탄소 $(\mathrm{CFC})$ 및 수소화염화불화탄소 $(\mathrm{HCFC})$ 는 우수한 열역 학적, 화학적 성질과 높은 안정성으로 인해 다양한 냉동/공조 분야에서 널리 사용되어 왔다. 그러나 1970년대 중반 $\mathrm{CFC}$ 들이 성층권의 오존층을 파괴한다는 사실이 알려지면서 선 진국들은 몬트리올 의정서에 의거하여 1996년 1월 1일부터 $\mathrm{CFC}$ 사용량을 동결하고 2009년 말까지는 $\mathrm{CFC}$ 를, 2029년 말까지는 $\mathrm{HCFC}$ 를 전폐시키기로 합의하였다. ${ }^{1)}$

냉동/공조 산업에서 $\mathrm{CFC}$ 에 대한 사용이 규제됨에 따라 오존파괴지수(Ozone Depletion Potential, ODP)가 0인 대체냉매를 찾기 위한 연구와 개발 활동이 활발하게 수행되었다. 이 러한 노력의 결과로 $\mathrm{HFC134a}$ 가 기존의 사용 되었던 $\mathrm{CFC} 12$ 의 대체냉매로 개발되어 지난 십 년간 가정용 냉장고와 정수기 등에 적용되 었다. 그러나 최근에 지구온난화 문제가 환경 적 이슈로 떠오르면서 1997년 교토의정서에 서는 $\mathrm{HFC}$ 를 포함한 온실가스를 규제할 것을 제안했다. ${ }^{2)}$ 따라서 현재 전 세계는 $\mathrm{HFC} 134 \mathrm{a}$ 를 대체할 수 있는, 환경적으로 안전하고 에 너지 효율이 우수한 대체냉매를 시급히 개발 해야 할 상황이다.
현재 많은 나라에서는 탄화수소 냉매를 가 정용 냉장고와 정수기 등과 같은 밀폐형 시스템 의 대체냉매로 채택하고 있다. 전통적으로 탄화 수소 냉매는 안전에 대한 문제로 일반적인 냉동 /공조 설비에 적용되지 않았으나 최근 환경 보 호에 대한 국제적인 요구로 인해 탄화수소 냉매 는 냉동/공조기에서 순수 작동유체나 혹은 두 가지 이상의 순수냉매가 혼합된 혼합냉매의 형 태로 여러 시스템에 적용되어 왔다. ${ }^{3,4)}$

냉동/공조기의 대체냉매를 선정할 때에는 제조비용을 최소화하기 위해 가능한 한 기존 의 장비를 변화시키지 않고 대체냉매를 효과 적으로 적용할 수 있는 'Drop in' 대체 기술을 적용하는 것이 바람직하다. 그러나 여러 연구 자들은 압축기를 재설계하지 않고서는 기존 의 냉매를 다른 순수 냉매로 대체하는 것이 쉽지 않음을 보고하였다. ${ }^{5,6)}$

혼합냉매를 적용할 때에는 가능한 한 온도 구배가 없거나 작은 공비의 근공비 혼합냉매 를 사용하는 것이 시스템 내의 누출로 인한 조성 분리 현상을 최소화 할 수 있어 시스템 안정성 확보에 효과적이다.

대체냉매의 최적 충전량을 결정하는 것은 대체냉매를 찾아내는 것만큼이나 중요하다. Houcek and Thedford ${ }^{7)}$ 는 시스템의 용량과 성능계수 $(\mathrm{COP})$ 를 최적화하는 충전량이 있고 최적 충전량을 벗어난 경우에는 성능이 점차 감 소한다고 보고했다. Frazad and $\mathrm{O}^{\prime} \mathrm{Neal}^{8)}$ 은 모 세관 팽창장치를 가진 공기조화기의 냉매충전 량을 변화시키면서 실험을 수행하여 냉매충전 량의 영향을 규명하였다. 또 Choi and $\mathrm{Kim}^{9}$ 은 냉매의 충전량 변화에 따른 냉매의 유량 변화가 시스템의 성능에 큰 영향을 준다고 밝혔다.

본 연구에서는 현재 가정용 정수기 냉동시 스템에 사용되고 있는 $\mathrm{HFC134a를} \mathrm{대체하기}$ 위해 새로운 혼합냉매인 R435A를 선정하고 Pull-down 테스트를 수행해 냉매 대체 가능 성을 확인해 보고자 한다. R435A는 질량비(mass fraction)로 $20 \%$ 의 R $152 \mathrm{a}$ 와 $80 \%$ 의 RE 170 으 
로 구성되었으며 온도 구배가 $0.1^{\circ} \mathrm{C}$ 보다 작아 서 조성 분리가 거의 없는 근공비 혼합냉매이 다. 최근에 R435A는 미국공조냉동학회에서 공식적으로 냉매 번호를 부여받아 냉동/공조 산업계에 제공되고 있다. ${ }^{10)}$

또한 R435A는 오존파괴지수가 없고, 지구 온난화지수도 상대적으로 적은 30의 값을 가 져 현재 가정용 정수기에 사용되고 있는 $\mathrm{HFC1} 134 \mathrm{a}$ 를 대체할 수 있는 친환경 냉매이다. 따라서 본 연구에서는 먼저 기존의 정수기 냉동시 스템에서 $\mathrm{HFC134a를} \mathrm{충전한} \mathrm{경우의} \mathrm{Pull-down}$ 테스트를 수행하여 성능을 측정하려 한다. 그 뒤 기존의 정수기에 $\mathrm{R} 435 \mathrm{~A}$ 를 충전하여 냉매 충전 량을 변화시켜가며 Pull-down 테스트를 수행하여 $\mathrm{HFC134a}$ 의 결과와 비교하여 대체 냉매로서의 가능성을 평가하려 한다.

\section{2. 열역학적 사이클 시뮬레이션 분석}

먼저 가정용 정수기 냉동시스템에 $\mathrm{HFC134a}$ 와 R435A를 충전하여 Pull-down 테스트를 수행하기 전에 컴퓨터 사이클 모사 프로그램 을 이용하여 실험 결과를 미리 예측하고 분석 할 필요가 있다. Fig. 1은 정수기 내부의 개략 도를 보여 준다. 냉수가 담기는 냉수탱크는 정수기의 윗부분에 설치되어 있고 냉동시스 템의 증발기 역할을 하는 증발 코일이 냉수탱 크 안에 들어있어 냉동기가 작동하기 시작하 면 증발 코일이 물과 직접 접촉하여 냉수를 냉각시켜 주고 마지막에는 냉각 코일 주변에 얼음이 생기게 한다. 밀폐형 압축기는 증발기 에서 증발한 냉매증기가 응축되기 쉽도록 냉 매의 압력을 높이고 모세관은 팽창기구로서 이용된다. 응축기는 정수기의 뒷부분에 설치 되어 자연대류를 통해 열을 외부로 방출한다.

Fig. 2는 정수기의 기본적인 냉동 사이클을 보여준다. 시스템 내의 냉매는 냉수 탱크에서 물과의 직접 열교환을 통해 증발하고 과열증기 상태로 증발기를 나간다(상태 1), 증발이 일어
나는 동안에 순수 냉매의 증발 온도는 일정하지 만 혼합냉매의 증발 온도는 올라가게 된다(온도 구배 현상). 증발기를 나온 증기상태의 냉매는 압축기에 의해 고온 고압의 과열 증기로 압축된 다(상태 2). 압축기를 나온 증기상태의 냉매는 응축기에서 액체상태의 냉매로 변화하고 응

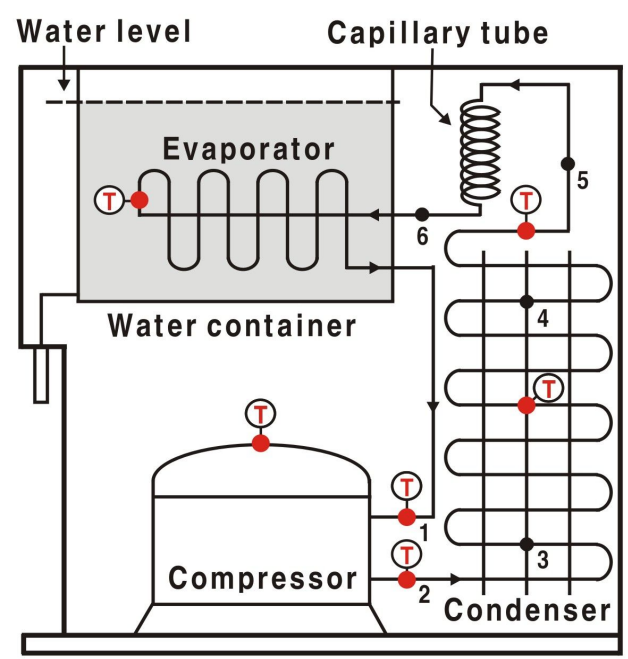

Fig. 1 Refrigeration system for domestic water purifier.

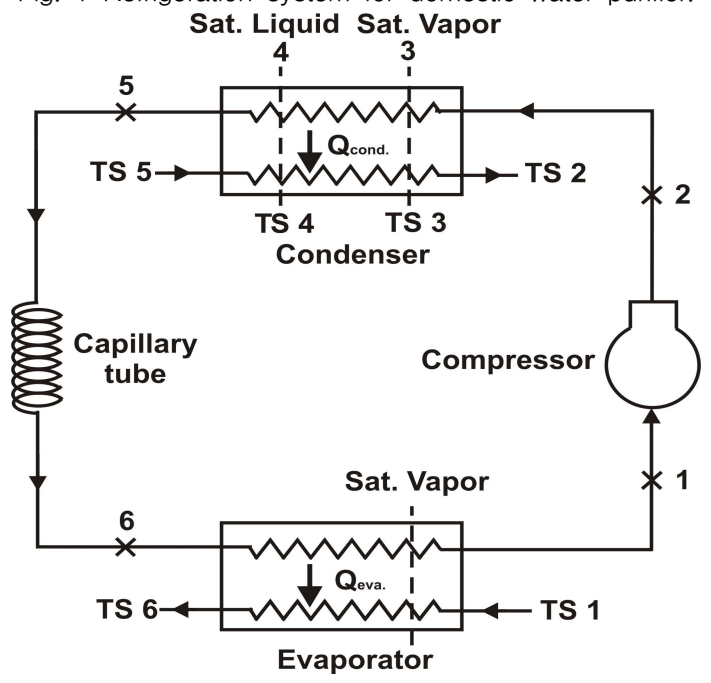

Fig. 2 Schematic of a single evaporator refrigerator for water purifiers.

축기 출구에서의 냉매는 과냉 상태이거나 2상 상태가 된다(상태 5). 마지막으로 응축기를 
Table 1. Simulation results

\begin{tabular}{c|c|c|c|c|c|c|c}
\hline Refrigerant & COP & $\begin{array}{c}\text { Diff. in COP } \\
(\%)\end{array}$ & $\begin{array}{c}\text { VC } \\
\left(\mathrm{kJ} / \mathrm{m}^{3}\right)\end{array}$ & $\begin{array}{c}\text { Diff. in VC } \\
(\%)\end{array}$ & $\begin{array}{c}\text { Tdis } \\
\left({ }^{\circ} \mathrm{C}\right)\end{array}$ & $\begin{array}{c}\dot{m}_{r} \\
(\mathrm{~g} / \mathrm{s})\end{array}$ & $\begin{array}{c}\text { Work } \\
(\mathrm{W})\end{array}$ \\
\hline HFC134a & 1.836 & & 1348 & & 93.2 & 26.2 & 1906.4 \\
\hline R435A & 2.138 & 16.4 & 1379 & 2.3 & 106.3 & 11.3 & 1637.3 \\
\hline
\end{tabular}

나온 냉매는 모세관을 통해 팽창 과정을 거쳐 하나의 사이클을 완성한다(상태 6).

본 연구에서는 $\mathrm{HFC} 134 \mathrm{a}$ 와 R435A에 대한 열 역학적 해석을 위해 냉동기의 열역학적 시뮬레 이션 프로그램 모델로 Jung and Rademacher ${ }^{11)}$ 가 제시한 UA-모델을 사용하였다. $\mathrm{HFC134a}$ 를 작동유체로 사용하고 있는 정수기의 증발 기와 응축기의 포화 온도는 일반적으로 각각 $-5^{\circ} \mathrm{C}$ 와 $50^{\circ} \mathrm{C}$ 정도이다. 열교환기의 성능은 열 교환기의 총괄열전달계수 $(\mathrm{U})$ 와 열교환기의 면적 $(\mathrm{A})$ 을 곱한 $\mathrm{UA}$ 값으로 나타낸다. 이 값 은 $\mathrm{HFC} 134 \mathrm{a}$ 를 적용할 때 정수기 냉동 사이 클의 온도가 증발기와 응축기에서 각각 $-5^{\circ} \mathrm{C}$ 와 $50^{\circ} \mathrm{C}$ 가 되는 값으로 정하였고 $\mathrm{R} 435 \mathrm{~A}$ 에서 도 동일한 $\mathrm{UA}$ 값을 사용하여 계산하였다. 또 한 압축기는 등엔트로피 과정으로 가정하였 다. 마지막으로 시뮬레이션에 필요한 변수와 시스템이 만족시켜야만 하는 평형 방정식을 연결하는 비선형 방정식 군을 풀기 위해 Jung and Radermacher ${ }^{11)}$ 가 이용한 Newton-Rahpson 방법을 이용하였다. Newton-Rahpson 방법은 나머지 식들이 0이 되게 하는 수치를 찾기 위한 초기 추정 값을 필요로 한다. 모델링에 관한 더 자세한 정보는 Jung and Radermacher ${ }^{11)}$ 의 논문을 참조하기 바란다.

사이클 모사에 필요한 모든 열역학적 물성 치는 미국 표준연구소에서 개발된 물성치 계 산 프로그램인 REFPROP 8.0 ${ }^{12)}$ 에 의해 계산 되었다. Table. 1은 이러한 컴퓨터 사이클 모 사 프로그램의 결과를 정리한 것이다. 사이클 모사 프로그램 결과를 살펴보면 $\mathrm{R} 435 \mathrm{~A}$ 를 적 용하는 경우 $\mathrm{COP}$ 와 체적 용량이 $\mathrm{HFC} 134 \mathrm{a}$ 에 비해 증가하며 압축기 토출온도는 $\mathrm{HFC} 134 \mathrm{a}$
보다 $13^{\circ} \mathrm{C}$ 높은 값을 가짐을 알 수 있다.
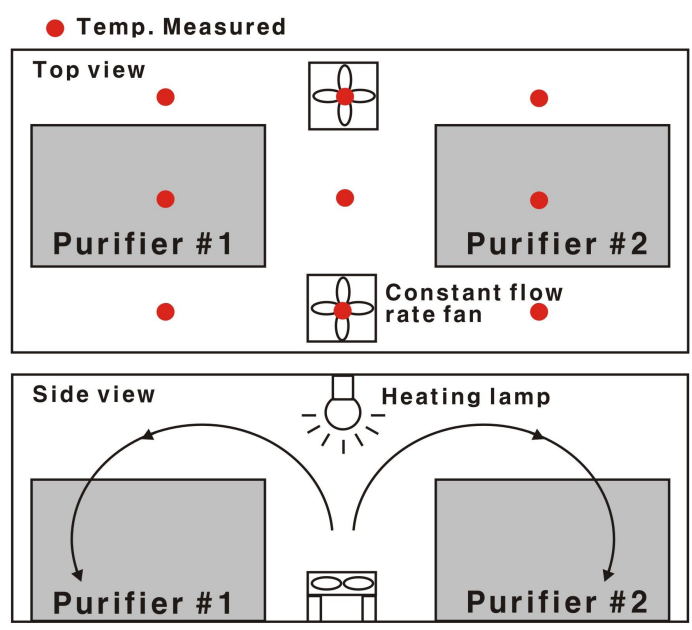

Fig. 3 Schematic of the inside of the constant temperature chamber.

\section{3. 실험 장치 및 실험 방법}

본 연구에서는 $\mathrm{HFC} 134 \mathrm{a}$ 와 $\mathrm{R} 435 \mathrm{~A}$ 를 충전 한 가정용 정수기의 Pull-down 테스트를 수 행하기 위해 외기온도를 일정하게 유지시킬 수 있는 항온 챔버를 제작하였다. 항온 챔버 는 상단에 백열등 2 개를 설치하여 온도 조절 에 필요한 열량을 공급하였고, 챔버 하단에 동일한 유속을 일정하게 낼 수 있는 팬 2 개를 설치하여 항온 챔버 내부에 온도가 균일하게 유지되도록 하였다. Fig. 3은 정수기 Pull-down 테스트를 수행할 수 있는 항온 챔버의 개략도 를 보여 준다. Fig. 3에서 위의 그림은 항온 챔버를 위에서 내려다본 것이다. 실험에서는 챔버 내부의 온도가 균일하게 유지되는 것을 확인하기 위해 내부를 9 부분으로 나누어 내 
부의 온도를 측정하였다. Pull-down 테스트 를 수행할 때 정수기가 가정에서 실제로 설 치되는 환경과 유사하게 만들기 위해 정수 기의 방열판이 챔버 벽 쪽으로 향하도록 설 치하였다. 또, 가능한 한 챔버 내부의 팬에서 불어오는 공기의 유동에 의해 방열판이 영 향을 받지 않도록 하였다. 챔버 내부의 벽면 에 정수기를 가까이 설치하게 되면 방열판 에서 방열되는 열량이 냉동시스템에 영향을 줄 수 있으므로 정수기를 벽면에서 $5 \mathrm{~cm}$ 정 도 떨어뜨려 설치하였다.

본 연구에서 사용한 정수기 시스템은 (주) 웅진코웨이 $\mathrm{CP}-07 \mathrm{BLO}$ 모델로 압축기 용량 이 $44 \mathrm{kcal} / \mathrm{hr}$ 인 것을 사용하였다.

Pull-down 테스트는 두 대의 정수기를 이 용해 수행하였다. 정수기 두 대 중 한 대는 테 스트마다 동일한 결과를 내는지 살펴보아 실 험에 문제가 있는지 여부를 알아보기 위한 기준으로 사용되었고 나머지 한 대는 실제 테 스트 결과를 얻기 위해 사용하였다.

Pull-down 테스트는 외기온도 $35^{\circ} \mathrm{C}$, 냉수 탱크 안의 물의 온도를 $30^{\circ} \mathrm{C}$ 로 맞춘 뒤 시작 하였다. 항온 챔버 내부 온도와 냉수 탱크의 물의 온도가 설정조건에 맞추어졌을 때 정수 기의 압축기에 동력을 공급하는 전원을 연결 하여 실험을 수행하였다. 냉수 탱크의 초기 물의 온도가 $30^{\circ} \mathrm{C}$ 에서부터 떨어지기 시작하 여 약 $5^{\circ} \mathrm{C}$ 가 되었을 때 정수기 냉동시스템은 자동으로 종료가 되도록 하였고, 만일 물의 온도가 $5^{\circ} \mathrm{C}$ 에 도달하지 못하였을 경우에는 Pull-down 테스트 시간이 150분이 지나면 정 수기 냉동시스템이 자동으로 종료가 되도록 제어하였다. 모든 실험에서 냉수 탱크 내의 물의 양은 8.2 리터로 동일하게 유지하였다.

Fig. 1 의 개략도에 있듯이 정수기 냉동 사이 클의 4 부분에서 온도를 측정하였다.

(1) 냉수탱크안의 증발기 (Water container)

(2) 압축기 입구 (Comp. in(Suction)

(3) 압축기 출구 (Comp. out(Discharge)

(4) 응축기 출구 (Condenser out)
Pull-down 테스트가 진행되는 동안 정수 기 냉동시스템의 각 부분의 온도를 정확하게 측정하기 위해 정밀도가 $\pm 0.1^{\circ} \mathrm{C}$ 인 T-type 열 전 대를 이용하였다. 또한 Pull-down 테스트 가 진행되는 동안 냉동시스템의 압축기에 들 어가는 소요 동력은 정밀도가 $\pm 0.2 \%$ 미만인 적산전력계(Watt meter)를 이용하여 측정하 였다.

Pull-down 테스트가 진행되는 동안 4개 부 분에서 열전대를 통하여 측정된 온도 데이터 와 적산전력계를 통해 측정된 압축기 소요 동 력은 데이터 로거(Data logger, HP34970)에 서 수집되어 컴퓨터의 하드디스크에 저장되 었다. 모든 데이터는 10 초 간격으로 측정하였 다. 컴퓨터에 전송되어 저장된 데이터는 Pull-down 테스트가 종료된 후에 데이터 해 석을 위한 프로그램을 이용하여 분석하였다.

테스트를 수행하기에 앞서 각 냉매의 최적 충전량이 알려지지 않았기 때문에 $\mathrm{HFC134a}$ 와 R435A의 액체 밀도를 비교하여 대략적인 충전량을 결정하였다. 물성치 계산 프로그램 인 REFPROP $8.0^{12)}$ 을 이용하여 $50^{\circ} \mathrm{C}$ 의 응축 기 온도에서 구한 $\mathrm{HFC} 134 \mathrm{a}$ 와 R435A의 액체 밀도는 각각 $1102 \mathrm{~kg} / \mathrm{m}^{3}$ 와 $647 \mathrm{~kg} / \mathrm{m}^{3}$ 이다. 이 밀도를 이용하여 $\mathrm{R} 435 \mathrm{~A}$ 의 초기 충전량은 $24 \mathrm{~g}$ 으로 정하여졌다. 실제 실험에서는 이렇 게 정해진 충전량을 토대로 해서 냉매의 충전 량의 변화에 따른 정수기 냉동시스템의 성능 을 살펴보고 최적의 냉매충전량을 제시하였 다. 이를 위해 HFC134a의 밀도비를 이용하 여 구한 각 냉매의 충전량을 $1 \mathrm{~g}$ 단위로 변화 시켜 가며 Pull-down 테스트를 수행하였다.

정수기 냉동시스템의 압축기에 들어가는 윤활유는 냉매와 혼합되어 시스템 내부에서 순환하기 때문에 대체냉매의 성능 평가 시 올 바른 윤활유를 선정하는 것은 매우 중요하다. 본 연구에서는 가능한 한 기존의 압축기나 윤 활유를 바꾸지 않아도 되는 'Drop-in' 냉매를 선정하는 데 초점을 맞추었으므로 기존에 
Table 2 Summary of test results

\begin{tabular}{c|c|c|c|c|c|c|c}
\hline \multirow{2}{*}{ Refrigerant } & $\begin{array}{c}\text { Charge } \\
(\mathrm{g})\end{array}$ & $\begin{array}{c}\text { Starting } \\
\text { temp. } \\
\left({ }^{\circ} \mathrm{C}\right)\end{array}$ & $\begin{array}{c}\text { Ending } \\
\text { temp. } \\
\left({ }^{\circ} \mathrm{C}\right)\end{array}$ & $\begin{array}{c}\text { Operating } \\
\text { time } \\
(\mathrm{min} .)\end{array}$ & $\begin{array}{c}\text { Energy } \\
\text { consumption } \\
(\mathrm{W} \cdot \mathrm{h})\end{array}$ & $\begin{array}{c}\text { Diff. in EC } \\
(\%)\end{array}$ & $\begin{array}{c}\text { Tdis } \\
\left({ }^{\circ} \mathrm{C}\right)\end{array}$ \\
\hline \multirow{2}{*}{ HFC134a } & 42 & 30.8 & 5.6 & 109.7 & 228.2 & & 93.5 \\
\hline \multirow{3}{*}{ R435A } & 20 & 30.6 & 15.1 & 149.2 & 199.3 & -12.7 & 70.9 \\
\cline { 2 - 8 } & 21 & 31.0 & 5.4 & 121.5 & 201.2 & -11.8 & 85.6 \\
\cline { 2 - 8 } & 22 & 30.7 & 5.4 & 103.8 & 184.5 & -19.1 & 89.9 \\
\cline { 2 - 8 } & 23 & 30.6 & 5.5 & 99.0 & 186.5 & -18.3 & 87.1 \\
\hline
\end{tabular}

$\mathrm{HFC134a}$ 시스템에 사용되어 온 에스테르계 오일을 그대로 사용했다.

\section{4. 실험결과 및 고찰}

본 연구에서는 가정용 정수기 냉동시스템 에서 친환경 대체냉매인 R435A와 기존에 쓰 이던 $\mathrm{HFC134a}$ 의 냉동 성능을 측정하고 비교 분석하였다. Table 2는 $\mathrm{HFC134a}$ 와 R435A에 대한 Pull-down 테스트 결과를 요약하여 보 여 준다. R435A를 정수기 냉동 사이클에 적 용하기 위해서는 먼저 적정량의 충전량을 결 정해야 한다. 앞에서 설명한 바와 같이 액체 밀도를 이용하여 결정한 $\mathrm{R} 435 \mathrm{~A}$ 의 충전량은 $24 \mathrm{~g}$ 이다. 그러나 Pull- down 테스트를 $24 \mathrm{~g}$ 에 서 진행한 결과 과충전이 되어 시스템이 불안 정하게 종료되는 것을 확인하였다. 따라서 $\mathrm{R} 435 \mathrm{~A}$ 의 경우 충전량을 $23 \mathrm{~g}$ 부터 $1 \mathrm{~g}$ 씩 줄여 가면서 실험을 수행하였다.

Fig. 4는 Pull-down 테스트가 진행되는 동 안에 냉수탱크 안의 물의 온도가 시간에 따라 변화하는 추이를 보여 준다. Fig. 4에서 볼 수 있듯이 Pull-down 테스트 결과는 냉매 충전 량에 따라 매우 크게 영향을 받았다. 이러한 결과는 정수기 냉동시스템 내의 초기 체적이 매우 작고 충전량의 절대량 또한 매우 적기 때문에 $1 \mathrm{~g}$ 의 충전량 변화에도 테스트 결과가 매우 민감하게 변하는 것을 보여 준다. 냉매 의 충전량이 $20 \mathrm{~g}$ 일 때에는 충전량이 부족해

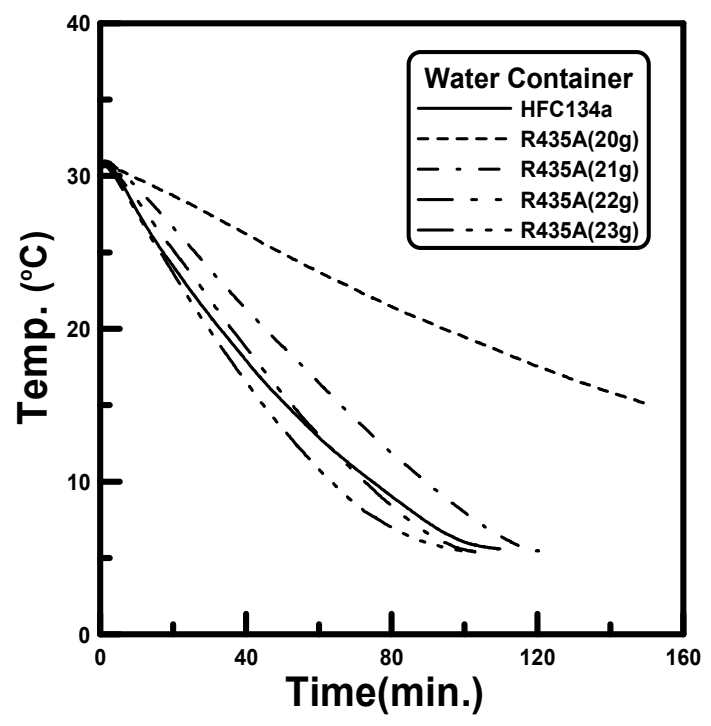

Fig. 4 Water temperature during pull-down tests.

증발기에서 요구되는 냉동 효과를 내지 못하 였고, $21 \mathrm{~g}$ 일 때에는 $\mathrm{HFC} 134 \mathrm{a}$ 의 결과와 유사 한 냉동 효과를 냈다. 또한 Table 2 의 결과에 서 알 수 있듯이 $\mathrm{R} 435 \mathrm{~A}$ 의 최적 충전량은 $21 \mathrm{~g}$ 정도로 나타났다. 냉매의 충전량이 $21 \mathrm{~g}$ 일 경우 온도를 끌어내리는 시간이 HFC134a에 비해 약 10 분 정도 더 소요되지만 에너지 소비량 (EC)은 $11.8 \%$ 정도 줄어드는 것을 알 수 있다. 테스트에 앞서 수행한 정수기 냉동 사이클 전산 해석에서 $\mathrm{R} 435 \mathrm{~A}$ 의 성능계수(COP)는 $\mathrm{HFC134a}$ 에 비해 $16.4 \%$ 정도 높은 것으로 나타났다. 그러나 실제Pull-downp 테스트에서는 그보다 낮은 $11.8 \%$ 의 향상을 보였다. 이러한 차이는 


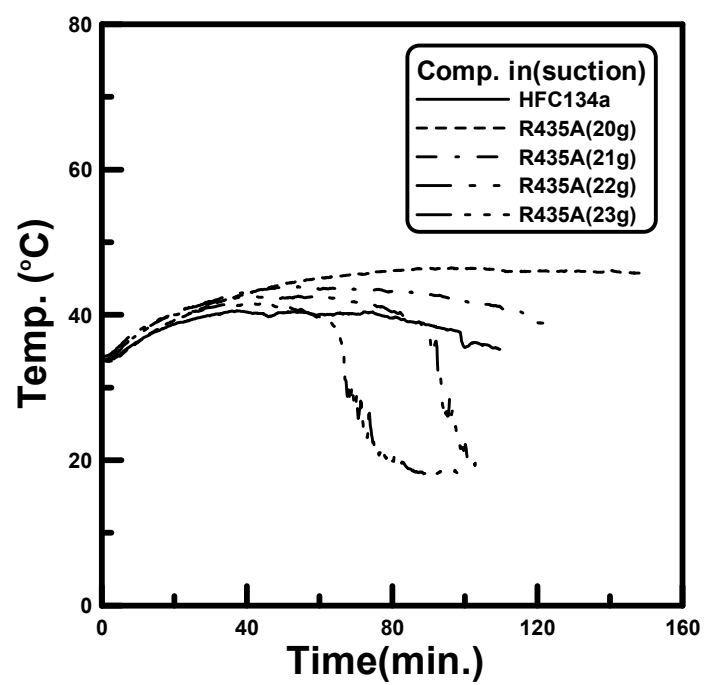

Fig. 5 Evaporator exit temperature during pull-down tests.

모세관의 길이가 $\mathrm{R} 435 \mathrm{~A}$ 에 최적화되어 있지 않고 윤활유도 R435A에 가장 적합한 것이 아니기 때문에 발생하는 것으로 사료된다. Fig. 5와 Fig. 6은 압축기의 입구와 출구의 온도를 보여 준다. Fig. 5에서 확인할 수 있듯이 냉매 충전 량이 $20 \mathrm{~g}$ 일 경우 시스템에 충전된 냉매량이 부족하다는 것을 증발기측 과열도를 통해 알 수 있다. 냉매 충전량이 적정량보다 부족하게 되면 증발기에서 요구되는 냉매 유량이 감소 하게 된다. 이 경우 증발기 하류 부분에서 냉 매가 과열 증기로 변하게 되며 따라서 압축기 에서 요구되는 흡입 냉매의 비체적이 커져 실 제로 압축기에 들어가는 냉매의 질량유량이 감소하게 된다. 따라서 압축기의 체적효율이 감소하게 되어 궁극적으로는 압축기의 냉매 토출량이 감소하게 된다. 즉 압축기에서 동일 한 냉매량을 응축기에 보내기 위해서는 압축 기에서 요구되는 소요 동력이 증가하게 된다. 반대로 냉매 충전량이 적정량보다 많게 되면 증발기의 냉매의 유량이 증가하게 되어 냉동 능력이 상승하게 되지만 증발기 하류부분에 서 과열도가 감소하게 된다. 그러나 기존의 $\mathrm{HFC} 134 \mathrm{a}$ 에 대한 과열도는 약 $30^{\circ} \mathrm{C}$ 정도이기 때문에 과열도가 감소하여도 $10^{\circ} \mathrm{C}$ 정도로 시스템

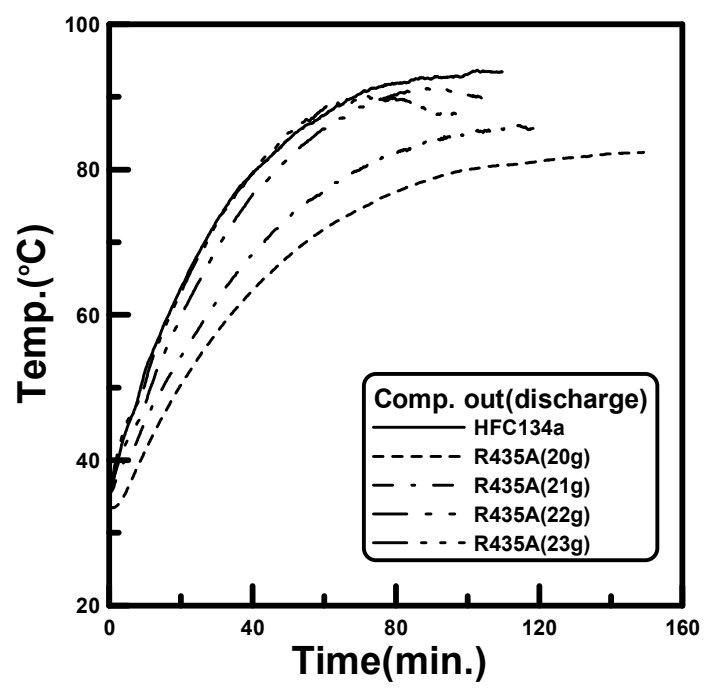

Fig. 6 Compressor discharge temperature during pull-down tests.

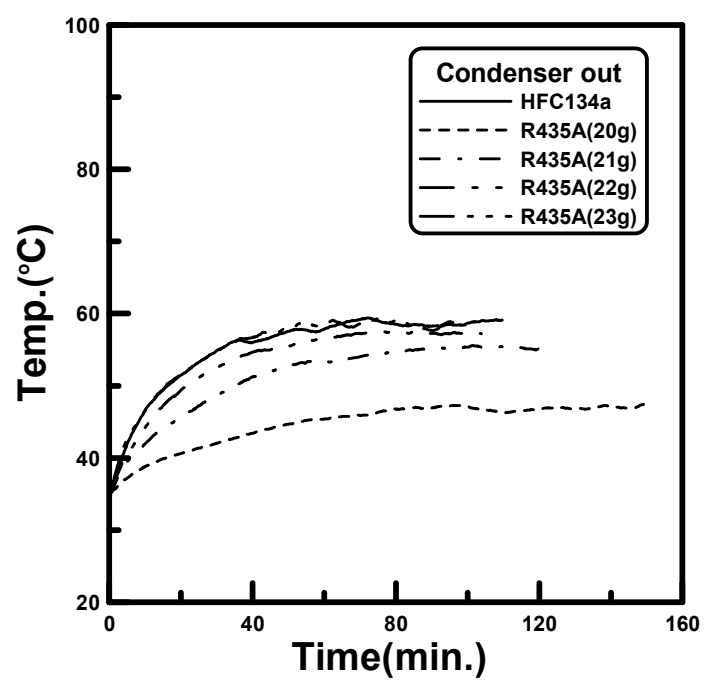

Fig. 7 Condenser exit temperature during pull-down tests.

에는 전혀 문제가 없다. 오히려 $10^{\circ} \mathrm{C}$ 정도의 적절한 과열도는 압축기의 체적효율을 증가 시켜 소요 동력을 감소시키는 효과를 가져오 는 것으로 나타났다.

Fig. 6과 Table 2에서 확인할 수 있듯이 $\mathrm{R} 435 \mathrm{~A}$ 의 충전량이 $21 \mathrm{~g}$ 일 경우 압축기의 평 균 토출온도는 $\mathrm{HFC} 134 \mathrm{a}$ 를 사용한 경우보다 $8^{\circ} \mathrm{C}$ 정도 낮아 시스템의 안정성 면에서도 압 
축기 토출온도만을 비교했을 때 R435A는 $\mathrm{HFC134a를} \mathrm{대체하는} \mathrm{데} \mathrm{큰} \mathrm{문제가} \mathrm{없을} \mathrm{것}$ 으로 생각된다.

Fig. 7은 응축기 출구의 온도 변화를 보여 준다. 냉매의 충전량이 증가할수록 압축기 토출 온도가 증가하여 응축기 출구의 온도도 증가 하는 경향을 보였다.

\section{5. 결 론}

본 연구에서는 가정용 정수기 냉동시스템 에 사용되고 있는 HFC134a 냉매를 대체하기 위해, $20 \%$ 의 R152a와 80\%의 RE170으로 구 성된 $\mathrm{R} 435 \mathrm{~A}$ 를 대체냉매로 선정한 뒤 Pull-down 테스트를 수행하여 냉동 성능을 측정하였다. 이를 위해 정수기 두 대를 동시 에 테스트할 수 있는 항온 챔버를 설계/제작 하였으며, 가정용 정수기에 대한 실험 조건 하에서 R435A의 충전량의 변화에 따른 정수 기 냉동시스템의 성능을 측정하였다. 각 냉매 의 Pull-down 테스트 결과를 바탕으로 다음 과 같은 결론을 얻었다.

(1) Pull-down 테스트 결과 R435A를 충전 한 정수기 냉동시스템의 성능은 충전량 에 따라 크게 영향을 받았다. 냉동시스 템의 체적이 매우 작고 냉매의 초기 충 전량 또한 매우 적기 때문에 $1 \mathrm{~g}$ 의 충전 량 변화에도 테스트 결과는 매우 민감 하게 변하였다.

(2) 본 연구에서 사용한 정수기 시스템에서 는 $\mathrm{R} 435 \mathrm{~A}$ 의 최적 충전량이 $21 \mathrm{~g}$ 으로 나 타났다. 냉매의 충전량이 $21 \mathrm{~g}$ 이 되면 온 도를 끌어내리는 시간이 HFC134a에 비해 약 10 분 정도 더 소요되지만 에너지 소비 량은 $11.8 \%$ 정도 줄어들었다.

(3) $\mathrm{R} 435 \mathrm{~A}$ 의 충전량이 $21 \mathrm{~g}$ 일 경우 압축기 의 평균 토출온도는 $\mathrm{HFC134a보다} 8^{\circ} \mathrm{C}$ 정도 낮아 $\mathrm{HFC134a를} \mathrm{대체하는} \mathrm{데} \mathrm{무}$ 리가 없을 것으로 생각된다.
(4) 본 연구에서는 기존의 압축기와 윤활유를 바꾸지 않는 'Drop-in' 대체를 목적으로 하였기 때문에 기존의 정수기를 크게 변 화시키지 않고 테스트를 수행하였다. 따라 서 상업용으로 제품을 출시하려면 최적화 작업을 위해 충전량, 모세관, 윤활유 등 에 대한 연구를 더 수행하여야 한다.

(5) 본 연구에서 사용된 R435A는 오존층 파 괴를 일으키지 않고 지구온난화 지수가 $\mathrm{HFC} 134 \mathrm{a}$ 보다 현저히 낮아 친환경적이 며 정수기 냉동시스템에서 $\mathrm{HFC134a보}$ 다 우수한 성능을 내므로 $\mathrm{HFC134a를}$ 대체하기에 적합할 것으로 사료된다.

\section{후 기}

본 연구는 한국연구재단의 중견 연구자 지원 사업(No. 2012-0007233)을 통한 교육 과학기술부의 연구비 지원에 의해 이루어 졌습니다.

\section{참 고 문 헌}

1. United Nations Environment Programme, Montreal protocol on substances that deplete the ozone layer, Final Act, 1987.

2. Global Environmental Change Report, A brief analysis of the Kyoto protocol, Vol. IX, No. 24, December, 1997.

3. Kruse, H., The state of the art of the hydrocarbon technology in household refrigeration, Proceedings of the International Conferences on Ozone Protection Technologies, Washington, DC., USA, pp. 179-188, 1996.

4. Jung, D., Kim, C., Song, K. and Park, B., Testing of propane/isobutane mixture in domestic refrigerators, International Journal of Refrigeration, Vol. 23, No. 7, pp. 517-527, 2000.

5. Jetter, J. J., Smith, N. D., Ratanaphruks, 
K. N., Tufts, M. W. and Delafield, F. R., Evaluation of alternatives for HFC-134a refrigerant in motor vehicle air conditioning, Proceedings of the International Conference on Ozone Protection Technologies, Washington, DC., USA, pp. 845-854, 1996.

6. Jetter, J. J. and Delafield, F. R., Alternatives for $\mathrm{CFC12}$ refrigerant in automotive air conditioning, Proceedings of the International Conference on Ozone Protection Technologies, Baltimore, USA, pp. 366374, 1997.

7. Houcek, J. and Thedford, M., A research into a new method of refrigeration charging and the effects of improper charging, Proceedings of the First Annual Symposium on Efficient Utilization of Energy in Residential and Commercial Buildings, Texas A\&M Univ., TX, 1984,

8. Frazad, M. and $\mathrm{O}^{\prime}$ Neal, D. L., System performance characteristics of air conditioner over a range of charging conditions, I nternational Journal of Refrigeration, Vol. 14, No. 6, pp. 321-328, 1991.

9. Choi, E. and Kim, J., The effects of the refrigerant charge on the performance of an air conditioner with capillary tube expansions, Korean Journal of AirConditioning and Refrigeration Engineering, Vol. 14, No. 5, pp. 359-364, 2002.

10. ANSI/ASHRAE Addenda a, b, c, d, e, f, $\mathrm{g}$, and $\mathrm{h}$ to ANSI/ASHRAE Standard 34-2007, Designation and safety classification of refrigerants. ASHRAE June 2007.

11. Jung, D. and Radermacher, R., Performance simulation of single-evaporator domestic refrigerators charged with pure and mixed refrigerant, International Journal of Refrigeration, Vol. 13, No. 4, pp. 223
-232, 1991.

12. Lemmon, E. W., Huber, M. L. and McLinden, M. O., NIST Reference Fluid Thermodynamics and Transport Properties, REFPROP version 8.0, 2007. 